\title{
Alberto Carrillo-Linares (coord.), La Historia aprendida y enseñada. Reflexiones polifónicas. Sevilla: Editorial Universidad de Sevilla, 2015, 174 págs.
}

\section{El regreso del sujeto. Destellos egohistóricos}

La postmodernidad es un tiempo que contempla el regreso del sujeto al centro de las ciencias sociales. A menudo la llamada postmodernidad ha soportado una connotación negativa, muy especialmente en la esfera de la historiografía hispana, que ha condenado a esa polivalente palabra y a sus resultados intelectuales (el postmodernismo) como santo y seña del ataque inmerecido a la impoluta ciencia practicada por los cultivadores de Clío. Ya de manera precursora, el sociólogo español Jesús Ibáñez, hoy injustamente ignorado, proponía la necesidad de construir una concepción positiva de la postmodernidad. ${ }^{1}$ Él mismo suponía que tal tarea requería borrar la negatividad del término, afirmando su cualidad positiva. Por aquel entonces, Fredric Jameson ya había abierto parcialmente la espita asimilando el fenómeno postmoderno a una nueva lógica cultural. ${ }^{2}$ Lo que en Ibáñez era una voluntad comprensiva en Jameson se convierte en una invitación a edificar, dentro del magma postmoderno y frente al aprovechamiento conservador de la erosión de las viejas certezas, nuevos "mapas cognitivos" que nos orienten críticamente en el mundo ayudándonos a comprender las nuevas complejidades inherentes al capitalismo globalizado de nuestro tiempo. ${ }^{3}$

Aunque si nos paramos a pensar la cuestión con detenimiento, la contraposición modernidad/postmodernidad se presenta como una falsa disyuntiva porque la lógica cultural de capitalismo es de larga data y lo que se llama postmodernismo viene a ser una hipérbole de la modernidad, una suerte de hipermodernidad. ${ }^{4}$ En cualquier caso, el derrumbe del paradigma físico newtoniano ha contribuido a dibujar, desde la primera mitad del siglo XX, un nuevo horizonte que epistemológicamente ha afectado a la relaciones sujeto-objeto, aunque tal novedad tardó en encontrar aceptación dentro de la historiografía dominante. Finalmente, hoy asistimos a una poderosa centralidad del sujeto y a una coimplicación epistemológica que nos lleva a "recuperar a la vez lo que hay de subjetivo en el objeto y lo que hay de objetivo en el sujeto", lo que comporta, a su vez, postular el carácter paradójico del conocimiento social y del mismo concepto de verdad. $^{5}$

La hipermodernidad y la consiguiente hipersubjetividad de nuestra época, con sus luces y sus sombras, han conducido a la proliferación de múltiples cultivos de lo que se califica como la literatura del yo. Como pretende Alberto Carrillo-Linares, coordinador de esta obra y autor de la contribución introductoria, el texto objeto de nuestro

\footnotetext{
1 Jesús Ibáñez y otros, "Sociología crítica de la cotidianeidad urbana. Por una sociología desde los márgenes", Anthropos, 113 (1990): 64.

${ }^{2}$ Frederic Jameson, "The Cultural Logic of Late Capitalism”, New Left Review, Vol. 1, 146 (1984): 5793.

${ }^{3}$ F. Jameson, El postmodernismo revisado (Madrid: Abada, 2010).

${ }^{4}$ Este término se debe a Gilles Lipovetski, De la ligereza (Barcelona: Anagrama, 2016), aunque lo utilizamos sin compartir el aparato conceptual con el que lo rodea su autor.

${ }^{5}$ Jesús Ibáñez, El regreso del sujeto. La investigación social de segundo orden (Madrid: Siglo XXI), 30.
} 
comentario plasma un cierto ejercicio de egohistoria, género historiográfico muy en boga.

Como brillantemente señaló François Dosse, la "apuesta biográfica" implica y conlleva opciones epistemológicas e historiográficas de muy distinto rango y calado. ${ }^{6}$ Lo mismo podría postularse de la autobiografía. En cierto modo, las vías de materializar la descripción de una vida o de relatar la de uno mismo comportan maneras diversas de hacer historia. Como se verá, aunque previamente el coordinador había ofrecido un esquema de cuestiones, los diez participantes toman caminos no siempre convergentes ni suficientemente respetuosos del guion previo.

\section{Sujetos profesionales ante el subjetivo espejo de su historia}

El libro consta de la narración de diez vidas profesionales de otros tantos historiadores (seis) e historiadoras (cuatro) profesionales (excepto uno, Julio Anguita, que se autoproclama historiador frustrado), pertenecientes a distintas especialidades y nacidos entre 1928 y 1955. Estos testimonios se encuentran precedidos de una aportación preliminar a cargo de Alberto Carrillo-Linares, docente de historia contemporánea de la Universidad de Sevilla, centro universitario al que han estado o están vinculados, de una forma u otra, más de la mitad de los coautores. El profesor Carrillo nos explica que el contenido de la pregunta generatriz del libro interpelaba a estos diez historiadores con vistas a que evocaran la historia que aprendieron, desde la escuela a la universidad, y la que enseñaron desde las tribunas docentes e investigadoras que ocupan u ocuparon (la mayor parte están ya jubilados o a punto de pasar a esa condición). Dice su introductor que el resultado es:

[...] un (auto) retrato complejo, pluriforme, elaborado con varias capas, que permiten diferentes aproximaciones y enfoques de análisis y que, en definitiva, constituye una radiografía parcial de la Universidad española de las últimas décadas. Todo ello esbozado con pinceladas muy personales que, combinadas, aportan un todo polifónico a la obra ( $p$. 17).

Los textos, según parece, fueron elaborados en 2014 con motivo de unas jornadas sobre Educación y franquismo. La historia que nos enseñaron. La historia que aprendimos. La historia que enseñamos.

Se trata, en efecto, de diez testimonios valiosos tanto por lo que dicen como por lo que omiten y, sobre todo, como luego comentaré, porque, tras el sujeto que habla, palpita el habitus de un "campo" profesional, es decir, un conjunto de percepciones y apreciaciones, no necesariamente conscientes, compartido incluso por personas de ideología antagónica. ${ }^{7}$

\footnotetext{
${ }^{6}$ François Dosse, La apuesta biográfica. Escribir una vida (Valencia: Publicaciones de la Universidad de Valencia, 2007). Este magnífico libro del historiador francés contiene una exhaustiva explicación de las distintas modalidades del género biográfico practicado a través de la historia. Desde la perspectiva sociológica, ya Pierre Bourdieu retomó el tema de l'illusion biographique en su Autoanálisis de un sociólogo (Barcelona: Anagrama, 2006).

7 Tal abanico conceptual ha sido brillantemente acuñado por Pierre Bourdieu en algunas de sus obras fundamentales, como el precursor Le sens pratique (1980), o su Homo academicus (1984), y también Raison pratiques. Sur la théorie de l'action (1994), todos ellos traducidos al español y de amplia difusión.
} 
Respecto a su interés por lo que se dice, sin duda, el libro añade un caudal informativo a las fuentes que nos permite estudiar el campo de los historiadores en España, objeto que ha merecido un encomiable y sostenido interés en la Universidad de Zaragoza $^{8}$. A tal propósito, estamos ante un libro interesante, pero aquejado de una cierta falta de organicidad porque las contestaciones se ajustan irregularmente al plan preestablecido en la pregunta inicial. Así, al fin y a la postre, el retrato colectivo se torna friso de respuestas un tanto accidental y disperso. Y así, unos autores tiran por la vía de ceñirse a la narración de su experiencia discente y docente y la consiguiente evolución de sus ideas (eso parece que era la pretensión genuina), pero otros aprovechan para hacer un extenso alegato de sus opiniones historiográficas (como el de José L. Escacena Carrasco, vehemente defensor de la arqueología darwinista frente a lo que llama "historicismo cultural"); u otros, como Josep Fontana, esconden más que describen su vida e itinerario como alumno y luego profesor, porque el reputado historiador catalán opta, como ya ha hecho en otras ocasiones, por armar su discurso comparando los libros de texto de la II República con los del primer franquismo, manuales que hacen a modo de cerros-testigos de dos concepciones históricas opuestas. Por su parte, Julio Anguita pone su ejercicio egohistórico, no desprovisto de relevantes elementos informativos, al servicio de la erección de una suerte de leyenda personal: la de una frustración por no haber llegado a profesor universitario a causa de que se cruzaran en su vida la alcaldía de Córdoba y otras responsabilidades políticas.

El resto (Pilar Castro Alonso, Genaro Chic García, $\mathrm{M}^{\mathrm{a}}$ Isabel del Val Valdivieso, Enriqueta Villa Vilar, Ricardo García Cárcel, Dolores Ramos Palomo y José Luis Comellas García-Llera) se acogen más a un relato descriptivo de su formación y, por lo general, inciden poco o nada en la memoria detallada de los tiempos escolares en los niveles básicos, mientras que conceden mucho mayor espacio y relieve a su formación universitaria y a su carrera investigadora. Destaca, en mi opinión, la viveza de la narración escrita por la profesora Dolores Ramos acerca del camino que la lleva al cultivo de la historia de género. Desde otros tiempos y otras coordenadas ideológicas muy distintas, José Luis Comellas relata cómo se gestó su inclinación hacia la historia contemporánea. En general, autores y autoras se debaten entre hacer de su vida profesional una descripción expresiva o convertirla en una interpretación ex post facto. El tono interpretativo, con un punto de caricatura de su pasado, está presente en la aportación de Ricardo García Cárcel, que relaciona sus tres ciclos de acercamiento a la historia (como alumno, como historiador primerizo y como historiador veterano) con la preeminencia de mitos imperantes en el discurso histórico de cada época. En la mayoría de las ocasiones, rige en el relato un cierto tono académico como quien defiende ante un tribunal (los lectores y lectoras) su curriculum vitae.

\footnotetext{
8 Así queda plasmado en el Seminario permanente de historia de la historiografía "Juan José Carreras", auspiciado por la Institución Fernando el Católico de la Diputación de Zaragoza. Por lo demás, Gonzalo Pasamar e Ignacio Peiró son autores de un Diccionario de historiadores españoles contemporáneos (Madrid: Akal, 2002), espléndida herramienta. Además, véase Ignacio Peiró Martín, Historiadores en España. Historia de Historia y memoria de la profesión (Zaragoza: Prensas Universitarias de Zaragoza, 2013), y Gonzalo Pasamar, Apologia and Criticism. Historians and History of Spain, 1500-2000 (Oxford: Peter Lang, 2010). Las actividades del zaragozano seminario permanente de historia de la historiografía pueden seguirse en: Blog de Historiografía, https://blogdehistoriografia.wordpress.com/ [consulta 24 noviembre, 2016].
} 


\section{Representaciones, esquemas y retóricas del campo profesional de los historiadores}

El habitus de cualquier campo profesional segrega imágenes compartidas que a menudo están por encima de las divergencias políticas o de otra clase. ${ }^{9}$ Este libro de testimonios constituye un ejemplo meridiano de ese conjunto de representaciones modélicas que atraviesan la mirada académica cuando se posa en el interior de los espacios educativos de ayer y de hoy. En tal sentido, desde el punto de vista de la historia de la educación, es una fuente preciosa para comprender esas reglas no demasiado conscientes que rigen los juicios de valor sobre las instituciones escolares, juicios que naturalmente emanan de ese surtidor colectivo e inconsciente que llamo pensamiento pedagógico dominante. Este se encuentra hoy empapado de una aguda y defensiva fobia antipedagógica que vela el fondo de la cuestión, a saber, el fenómeno de la pedagogización del conocimiento inherente al modo de educación tecnocrático de masas.

A fin de hacer visible ese "Otro" desde el que se habla (permítaseme esta licencia lacaniana) me he ocupado de efectuar una sencilla agrupación de constantes valorativas, envueltas en una retórica corporativa, en los diez testimonios examinados, que dividiré en dos agrupaciones temáticas: por un lado, los referidos a la enseñanza básica y media; y, por otro, los vertidos acerca de la enseñanza universitaria. En cuanto a lo dicho sobre la primera de las agrupaciones, abundan los juicios de valor someros $\mathrm{y}$, en cambio, faltan toda clase de concreciones (son excepcionales los testimonios que recuerdan los libros en los que se aprendió historia, los profesores que la enseñaron, los métodos didácticos, etc.). Hay, eso sí, una amplia coincidencia en ensalzar el "bachillerato de siete años" del franquismo escolar de su adolescencia y en denigrar las reformas educativas emprendidas desde 1970 y especialmente las vinculadas a la denostada Ley de Ordenación General del Sistema Educativo (LOGSE) de 1990. Sobresale en este afán debelador contra la LOGSE la contribución de Julio Anguita, que ya en otro libro reciente nos había indicado en tono rotundo, como quien dice verdades como puños: "Fue un crimen. Y, claro, se ha notado". ${ }^{10}$ Lo que se nota es que a veces un tópico reaccionario cohabita sin molestias con un pensamiento afincado en la izquierda comunista. Incluso hay una autora, Enriqueta Vila Villar, que se detiene en señalar, en el mejor estilo de la "literatura del desastre" (no la del 98 sino la generada por la educación de masas), el descenso de la calidad de la enseñanza desde 1970 y la suerte de estudiar "sus siete intensos años de bachillerato" (p.110). Bachillerato de una persona nacida en 1935, que inferimos no puede ser otro que el ultrafascista Plan de 1938, urdido en plena guerra civil por el ministro Sainz Rodríguez. Y esa aserción la adereza con la genial y original idea de que uno de los problemas principales de España reside en que no existe estabilidad educativa como la que diera la Ley Moyano de 1857, lo que, según ella, vino a romperse con la Ley General de Educación de 1970 y otras que posteriormente han arruinado el imprescindible consenso educativo interpartidario. Quizás convenga decir aquí, a modo de contrapunto, que entre 1857 y 1900 hubo quince planes de estudios en bachillerato (en primaria en el siglo XIX ni siquiera los había, ¿para qué?). Tampoco procede ignorar que el Plan de Estudios de Bachillerato de 1975 fue uno de los más duraderos de la educación española (veinte años). O sea, que a

\footnotetext{
${ }^{9}$ Hemos estudiado este fenómeno en Raimundo Cuesta y Juan Mainer, "Guardianes de la tradición y esclavos de la rutina: historia del campo profesional de los catedráticos de Instituto", Historia y Memoria de la Educación, 1 (2015): 351-93.

${ }^{10}$ Julio Anguita/Juan Andrade, Atraco a la memoria. Un recorrido histórico por la vida política de Julio Anguita (Madrid: Akal, 2015), 343.
} 
efectos de estabilidad, cualquier tiempo pasado no fue mejor. En fin, la idealización del pretérito (o su menosprecio caricaturesco) representa un pobre sucedáneo del análisis riguroso. Ya se sabe, al mirar hacia atrás comparece el peligro de chocar contra dos escollos: una memoria almibarada o su contrario.

Si pasamos a comentar lo que se dice sobre la enseñanza y el aprendizaje de la historia en la universidad, entonces nos topamos con un panorama más rico en precisiones y algo más positivo acerca de las líneas de tendencia actuales, aunque aquí se despliega una mayor variedad interpretativa (por ejemplo, García Cárcel critica los mitos nacionalistas de su tiempo escolar, los excesos estructuralistas-marxistas y el relativismo del postmodernismo).

Aun así también es factible hallar retóricas y constantes compartidas. En efecto, en primer lugar ninguno de los intervinientes se plantea, ni por asomo, problematizar la presencia de la historia como disciplina escolar o como disciplina científica. La historia escolar se percibe como una realidad "natural", y lo mismo ocurre con la "historia científica", ambas aceptadas como un consenso implícito imperante en el interior de una comunidad epistemológica. ${ }^{11}$ Se comulga con una imagen positiva respecto al orden disciplinar heredado, aunque ello no evita que, dentro del mismo, se presenten paradigmas de aproximación diferentes (la arqueología darwinista, la historia racional, la historia de género, etc.).

Hay una amplia coincidencia, aunque no unánime, en estimar que la universidad en la que estudiaron (mayoritariamente en los años sesenta, que, ciertamente, fueron de apertura) era un oasis de libertad de cátedra y de balsámicas relaciones entre profesores y alumnos. Incluso alguno, como el profesor Comellas, que vivió la sombría universidad de la inmediata posguerra, no alude al terrible "desmoche" y sí, en cambio, habla resignadamente de las miserias y gabelas que cualquier aspirante había de sufrir dentro de aquel devastado solar intelectual. En realidad, por término general, se pasa de puntillas y hay un clamoroso silencio a propósito de las relaciones de saber-poder existentes entonces y ahora en el campo historiográfico. Empero sí se evoca con reverencia y cariño a los maestros como si un suave y encantador discipulado fuera una parte del Bildunsgroman de cada cual. En el fondo, los testimonios transparentan un tono complaciente y una visión feliz de la profesión a años luz de una sociohistoria crítica del campo intelectual. $^{12}$

A modo de balance, repetiré que los testimonios recogidos en el texto editado por la Universidad de Sevilla interesan tanto por lo que dicen como por lo que callan. En cuanto a su valor como fuente, en el caso de la historia de la educación sirve para confirmar la larga supervivencia de estereotipos mentales y retóricas escleróticas que

\footnotetext{
${ }^{11}$ Sin embargo, la historia de las disciplinas escolares y la historia de la ciencia pueden cuestionar estos consensos tácitos e inamovibles. Por ejemplo, para una problematización del "código disciplinar" de la historia escolar, véase Raimundo Cuesta, Sociogénesis de una disciplina escolar: la historia (Barcelona: Pomares, 1997).

${ }^{12}$ Tal como sugiere la sociología histórica que se centra no tanto en la verdad de las doctrinas como en las redes sociales que compiten por hacerse con la preeminencia del campo. Véase la magna obra de Randall Collins, Sociología de la Filosofía. Una teoría global del cambio intelectual (Barcelona: Herder, 2005). En esa misma dirección pero con un componente marcadamente bourdieuano, son recomendables los frutos cosechados por la "Escuela de Cádiz"; véase la obra de su principal mentor, Francisco Vázquez Díaz, La Filosofía española. Herederos y pretendientes. Una lectura sociológica (1963-1990) (Madrid: Abada, 2009).
} 
reaparecen a la hora de poner en marcha las reminiscencias sobre ese país extraño que es el pasado. Por lo que hace a su interés para conocer la evolución de la historiografía española, de las ideas históricas y de la enseñanza universitaria, estos destellos egohistóricos sí que ofrecen una serie de hechos y pautas interpretativas que añaden conocimiento sobre el habitus reinante entre los historiadores, punto de partida a la hora de abordar en el futuro un trabajo más riguroso sobre el campo profesional. Tarea estimulante, larga y todavía incompleta.

Raimundo Cuesta

Fedicaria-Salamanca

raicuesta2@gmail.com

Fecha de recepción: 16 de octubre de 2016.

Fecha de aceptación: 28 de octubre de 2016.

Publicación: 31 de diciembre de 2016.

Para citar este artículo: Raimundo Cuesta, "El regreso del sujeto. Destellos egohistóricos. Reseña de Alberto Carrillo-Linares (coord.), La Historia aprendida y enseñada. Reflexiones polifónicas. Sevilla: Editorial Universidad de Sevilla, 2015, 174 págs.", Historiografías, 12 (junio-diciembre, 2016): pp. 164-169.

http://www.unizar.es/historiografias/historiografias/numeros/12/cuesta.pdf 